\title{
A PROSPECTIVE STUDY OF SERUM FOLATE CONCENTRATION AND HEMOGLOBIN IN CERVIX CARCINOMA PATIENTS
}

\begin{abstract}
SHANNO KM ${ }^{1}$, DISHA SHARMA ${ }^{2}$, SUDHANSHU MISHRA ${ }^{3}$
${ }^{1}$ Department of Pharmacy, Banasthali Vidyapith, Jaipur, Rajasthan, India. ${ }^{2}$ Department of Pharmacy, Dr. M.C. Saxena College of Pharmacy, Lucknow, Uttar Pradesh, India. ${ }^{3}$ Department of Pharmacy, School of Pharmaceutical Science, Rajiv Gandhi Proudyogiki Vishwavidyalaya, Bhopal, Madhya Pradesh, India. Email: msudhanshu22@gmail.com
\end{abstract}

Received: 24 November 2020, Revised and Accepted: 04 January 2021

ABSTRACT

Objective: The study aimed to have a prospective study of serum folate concentration and hemoglobin (Hb\%) in cervical carcinoma patients.

Methods: The study was conducted on women suffering from carcinoma cervix. The research was conducted in the Gynecological Outpatient Department (OPD) of the Oncology Unit in Mahavir Cancer Sansthan Patna, Bihar. The study period was from May 2016 to April 2017 . The sample was collected after face to face interview by Figo staging and the sample was taken regularly. As a result strong association of $\mathrm{Hb} \%$ and carcinoma cervix was found with the mean value of lower than 11.12, which is lower than the normal range of $\mathrm{Hb} \%$. As per the further estimation of folic acid, the level of cervical cancer is low.

Results: The data were estimated with help of tools such as SPSS 16.0 and PRISMA 5.0. The Hb\% the mean value of patients was estimated to be lower than 11.12, which is not under the normal range of $\mathrm{Hb} \%$, that is, nearly $12.5 \mathrm{mg} / \mathrm{dl}$. The low mean value shows less $\mathrm{Hb} \%$ content which leads to anemia in normal beings as well as in patients with cervical cancer. A strong association of $\mathrm{Hb} \%$ which affected to patients in carcinoma cervix can be seen in the graph that the mean value of patients low $11.12 \pm 0.20$ which not comes under normal range of $\mathrm{Hb} \%$, that is, $12.5 \mathrm{mg} / \mathrm{dl}$. The $\mathrm{R}$ square value is 0.9556 .

Conclusion: As per our study, we have estimated that the folic acid level in cervical cancer is low. The -normal range of folic acid level in plasma serum is $2.2-20 \mathrm{ug} / \mathrm{ml}$. The mean of 20 control cases, new cervical cancer patients, on treating patients, and follow-up patients is 11.08 , 2.206, 3.554, and 2.783, respectively. The control 11.08 shows the better level in plasma serum level comes under a normal range of folic acid level.

Keywords: Cervical cancers, Human papillomavirus, Folic acid, ultraviolet/visible spectrophotometer, Absorbance, Hemoglobin.

(C) 2021 The Authors. Published by Innovare Academic Sciences Pvt Ltd. This is an open access article under the CC BY license (http://creativecommons.org/ licenses/by/4.0/) DOI: http://dx.doi.org/10.22159/ajpcr.2021v14i3.40367. Journal homepage: https://innovareacademics.in/journals/index.php/ajpcr

\section{INTRODUCTION}

As per the current scenario, one of the most wide-ranging gynae cancers among women is cervical which causes significant deaths in women around the world. It mostly occurs in the low economy or developing countries. Many types of cervical cancers expand from irregular cells at the aperture of the cervix and it is known as squamous cell carcinoma. The further development is from gland cells, but that is not common. Those tumors are called adenocarcinomas. It has been stated that there are approximately 12,000 women tested positive for cervical cancer per year. The diagnosis can be done in three types which are cervical cytology (Papanicolaou or "Pap" test), Pap/human papillomavirus (HPV) co-test, and HPV-only test [1]. There are almost one in five women diagnosed with cervical cancer in India and the country has the greatest load of such patients [2,3].

Another most reliable method of treatment of metastatic cervical cancer for years is platinum-based chemotherapy but has not shown any major improvements in survival rate [4,5]. The other causes of carcinoma cervix are etiological points various oncogenic microorganisms, dietary factors, low socio income group, immune system, and epigenetic factors $[6,7]$. This leads to understandable implications for primary avoidance, that is, vaccination and later secondary prevention, that is, screening. In most of the developing countries, screening and diagnosis are aimed at early classification of high-risk HPV lesions during HPV testing and Pap smears [8]. The most convincing reason for deaths is the loss of resource availability and it is thus considered a serious social health issue $[9,10]$.
As per the studies and patient perspective, cervical cancer is a sexually transmitted disease, thus it can be prevented. A study based on ethnic minority women in the United Kingdom specified some barriers against the diagnosis including low awareness, fright, awkwardness, and disgrace, and low professed risk $[3,11]$. At present, there are new compounds that are in trials with hopeful results and simultaneously there are also numerous new strategies that might cover the unmet need in cervical cancer [4].

As per the WHO and some studies, it has been already estimated that if the range of the hemoglobin ( $\mathrm{Hb} \%$ ) is approximate $>12 \mathrm{~g} / \mathrm{dL}$ for anemia in non-pregnant females over 15 years, it further significantly deteriorate acute mucocutaneous toxicity in patients with highly developed cervical cancer in patients with patients getting chemoradiation $[12,13]$.

As per the knowledge gathered, there are not many studies which are indicating an investigation of the folate status of any specific region of the country/state. Thus, we have conducted this kind of study in the Bihar region on women suffering from carcinoma cervix. Thus, the purpose of this prospective study was to identify nutritional factors (folic acid) deficiency associated with immunosuppressant of cervical cancers among patients.

\section{METHODS}

It is a prospective longitudinal cohort study with local patients (Northern region) followed over time. The investigation was quantitative, and the research design was mostly case-control. The study approach was mostly analytical and was employed to review the 
risk of folate production in cervical cancer patients. The research was conducted in the Gynecological Outpatient Department (OPD) of the Oncology Unit in Mahavir Cancer Sansthan Patna, Bihar. The consent was taken individually from every participant. Before the initiation of the study, the ethical approval was taken from the institute (MCS/ Admin/2016-17/1055/12).

The study period was from May 2016 to April 2017. The group was formed of similar patients (cohorts) who differ in respect to certain factors such as age at marriage, addiction, dietary habits (veg/nonveg), frequency of meal, and dairy products. The study was planned based on analytical analysis employed to assess factors that affect the outcome of the result. The patient who was taken into the inclusion criteria (Groups I-IV) was suffering from cervical cancer. The patients which were tested negative in the diagnosis of cervical cancer were dropped into the control group. As per the literature, the sample size of the group required to conduct parametric tests was reported to be at a minimum of 60 .

The study is been designed based on the previous study of Tiwari and Gupta (2008) is a simple and sensitive method designed to develop the estimation of ascorbic acid by ultraviolet (UV) spectrophotometry. In this method, Systronics UV-visible spectroscopy instrument is used for spectral estimation. Ascorbic acid is treated with potassium iodate-iodide solution under acidic conditions to liberate iodine. The Rhodamine - B dye was measured at $555 \mathrm{~nm}$. The concentration of 1.2-12 $\mu$ g ascorbic acid obeys the beer's law. Statistically, the method was accurate and precise [14].

All cases were qualified for the study if they met the criteria like that comes under inclusion criteria.

\section{Inclusion criteria}

The following criteria were included in the study:

- All diagnosed and confirmed patients of cervix cancer

- Age between 18 and 80 years

- Women willing to participate in the research study.

\section{Exclusion criteria}

The following criteria were excluded from the study:

- Women which are diagnosed with cervical dysplasia

- Defaulter patients (the patients who already counseled in another study)

- Patients who were diagnosed with other major disorders such as AIDs and HIV.

The sampling for cases was performed employing the detailing technique. All members of the study population taken as participants were made to fill the detail sheet about them and along with that, the diagnosis was properly studied. All participants available in the gynecology OPD during the data collection period were included in the study as per the fixed criteria.

\section{Sample size}

The total samples taken for the study were 200 patients which were divided into four groups. The study was conducted with a sum of 200 patients, with 180 cases and 20 controls. Apart from control, all the other groups had 60 patients each. Group I was the control which had healthy individuals. In Group II, individuals were new patients with cervix cancer before initiation of treatment, Group III had individuals which came during treatment, and Group IV had individuals who came during follow-up routine checkups after treatment. The followup patients were those who already completed their therapy and treatment and come to routine check-in 3 months.

\section{Tool for data collection}

Face-to-face interviews were conducted with participants. The diagnosis and the patient blood history helped us to collect the estimated value of the $\mathrm{Hb} \%$ of the patient. The questioner sheet was prepared as per the literature which was filled by each individual and the interview has consisted of a series of questions for collating information about a particular topic from patients individually. Questions were asked in Hindi and included identification detail (Name, contact, and address), any history of cancer in the family if yes give detail, marital status, religion, addiction, and dietary habits. There were questions about some fixed parameters such as menstrual history, body mass index, weight, blood group, and comorbidity. Any information related to the symptoms of carcinoma cervix was also noted. Finally, the social (Cause of coming in advance stage, who brought you to the hospital, etc.) and practical (diagnosis) assessment were also taken into consideration.

\section{Sample collection}

For sample collection, the patients were marked from mild-to-severe as per the scale of Figo staging, and samples were taken at the regular interval. The $\mathrm{Hb} \%$ rate was determined as per the standard laboratory procedure. The data were analyzed with the line graph. The rate of the hemoglobin varied as per the stage and the severity of the patient. Hemoglobin content decreased according to the cancer stage advancement.

\section{Hb\% estimation}

A strong association of $\mathrm{Hb} \%$ affected patients in carcinoma cervix (Fig. 1).

The $\mathrm{Hb} \%$ the mean value of patients was estimated to be lower than 11.12 which is not under the normal range of $\mathrm{Hb} \%$, that is, nearly 12.5 $\mathrm{mg} / \mathrm{dl}$. The low mean value shows less $\mathrm{Hb} \%$ content which leads to anemia in normal beings as well as in patients of cervical cancer.

\section{Data analysis}

Later for the estimation of the value of $\mathrm{Hb} \%$, the curve was created to estimate the probability of disease with the help of the statistical analysis. Data were statically analyzed by SPSS 16.0 to determine correlation between folate acid formation and the occurrence of cervix cancer. If the probability value is $<0.05$ so the data will be considered as statistically significant. Further suspected risk factors were analyzed for their outcome and determine the precaution and awareness for the protection of cervix cancer.

\section{Preparation of calibration curve} Reagent preparation

We prepared ascorbic acid (Lobachemie): There Stock sol. of $1000 \mathrm{~g} / \mathrm{ml}$ was prepared by taking potassium iodate $(0.2 / \mathrm{mol})$ and dissolving it in $100 \mathrm{ml}$ distilled water. After that, add potassium iodide $(0.1 / \mathrm{mol})$ dissolved in $100 \mathrm{ml}$ distilled water. Furthermore, add hydrochloric acid (0.02 mol/l) dissolved in $90 \mathrm{ml}$ distilled water and stir it properly and make it up to $100 \mathrm{ml}$.

For rhodamin blue $(0.05 \%$ aq solution): Dissolve it in distilled water and make it up to $100 \mathrm{ml}$. For sodium acetate $(2.0 \mathrm{~mol} / \mathrm{l})$ : Dissolve it in $10 \mathrm{ml}$ distilled water.

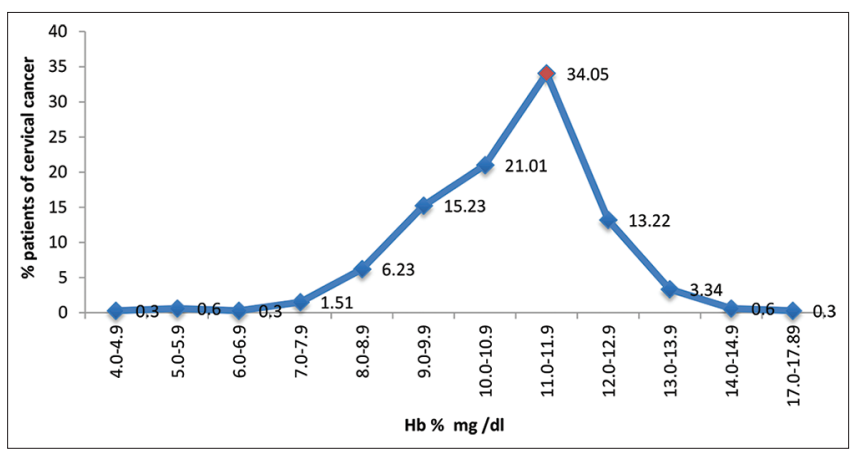

Fig. 1: Association of $\mathrm{Hb} \%$ which affected to patients in carcinoma cervix 
A stock solution of ascorbic acid

$100 \mathrm{mg}$ of ascorbic acid was weighed and transferred into a $25 \mathrm{ml}$ volumetric flask. Solubilized properly dissolve in distilled water. The volume was made up to $100 \mathrm{ml}$ with respective to get the final solubilization.

\section{Absorption maxima determination using UV/VIS spectrophotometer}

From the stock solution of $1000 \mu \mathrm{g} / \mathrm{ml}, 1 \mathrm{ml}$ aliquots were withdrawn and separately diluted with distilled water. In a calibrated volumetric flask, the solution $100 \mu \mathrm{g} / \mathrm{ml}$ was scanned in the range of $555 \mathrm{~nm}$ to determine using UV/visible spectrophotometer. Later in the results, it was found to be beyond Beer's range. Therefore, $1 \mathrm{ml}$ was aliquoted from the $100 \mu \mathrm{g} / \mathrm{ml}$ solution of stock solution was taken and diluted to $10 \mathrm{ml}$, hence getting the concentration of $10 \mu \mathrm{g} / \mathrm{ml}$. This solution was again scanned and absorption maxima was determined.

$10-50 \mu \mathrm{l}$ of ascorbic acid transferred to $25 \mathrm{ml}$ graduated tube separately. $0.4 \mathrm{ml}$ mixture of potassium iodide and potassium iodate pipette $1 \mathrm{ml}$ of 0.2 mole/l HCL were added. Then, the mixture was gently shaken, then yellow color was appeared (yellow color appearance indicates liberation of iodine). Then, $1 \mathrm{ml}$ of $0.5 \%$ Rhodamine blue solution was added to solution mixture followed by addition of $2 \mathrm{ml}$ of $0.2 \mathrm{~mol} / \mathrm{l}$ sodium acetate and then solution mixture and was shaken for $2 \mathrm{~min}$. The content was diluted up to $25 \mathrm{ml}$ with distilled water and the mixture was kept for 10-15 min. Then absorbance was measured on $\mathrm{UV}$ at $555 \mathrm{~nm}$

\section{Preparation of calibration curve (Figs. 2 and 3 )}

Reagent preparation

For ascorbic acid (Lobachemie) add stock sol. of $1000 \mathrm{~g} / \mathrm{ml}$ was prepared by dissolving $10 \mathrm{mg}$ of ascorbic acid in $100 \mathrm{ml}$ of water. For potassium iodate $(0.2 / \mathrm{mol}) 4.25 \mathrm{~g}$ was dissolved in $100 \mathrm{ml}$ distilled water

Potassium iodide $(0.1 / \mathrm{mol})$ was made by adding $1.660 \mathrm{~g}$ potassium iodide in $100 \mathrm{ml}$ distilled water. Hydrochloric acid (0.02 mol/l) was made by adding $17 \mu \mathrm{l}$ concentrated HCL in $90 \mathrm{ml}$ distilled water and stir it properly and make it up to $100 \mathrm{ml}$ by adding extra distilled water.

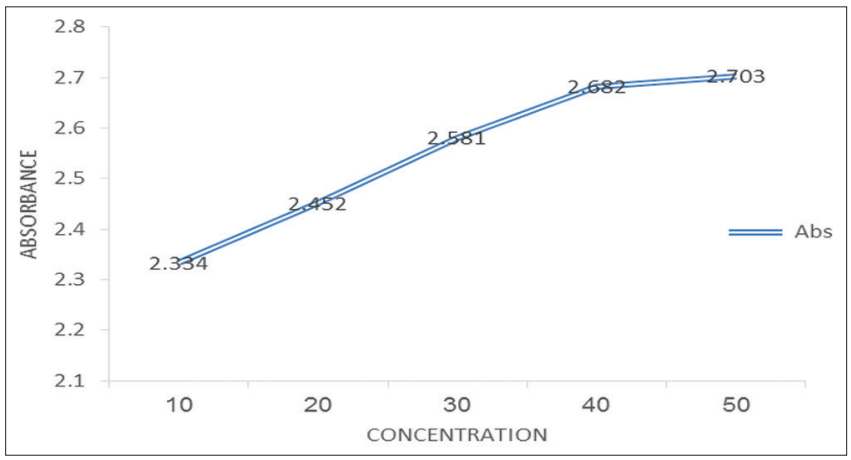

Fig. 2: Calibration curve of folic acid

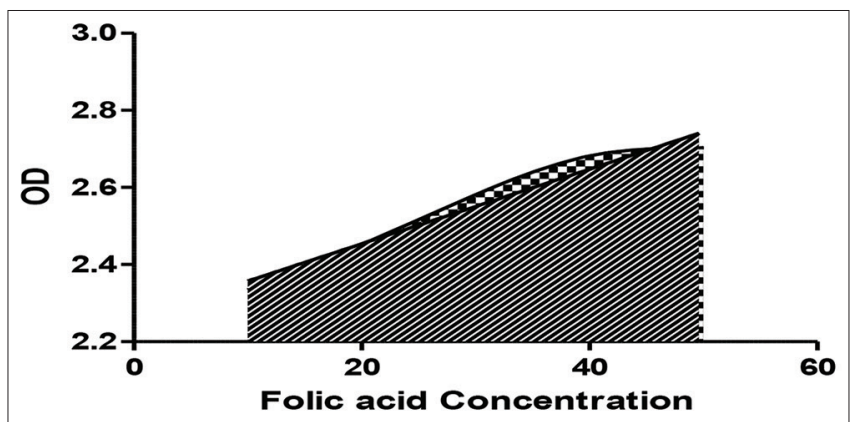

Fig. 3: Calibration curve of folic acid (prism software)
Rhodamin blue $(0.05 \%$ aq solution) was made by adding $0.05 \mathrm{~g}$ of rhodamin blue and was dissolved in distilled water and made it up to $100 \mathrm{ml}$.

Preparation of calibration curve of Folic acid in distilled water The calibration curve of folic acid was prepared in distilled water at 555 nm using a UV spectrophotometer. Beer's range [Ind. Council Chem., Vol. 25, No. 2, 2008] was found between 10 and $50 \mu \mathrm{g} / \mathrm{ml}$ and $\mathrm{R}^{2}$ was 0.955 the curve.

\section{Estimation of folic acid}

Later folate acid estimation was done by collecting the fresh blood sample of the patients, from the pathology department through intravenous. The folic acid assessment was done in almost 200 patients who were prepared to give blood samples to a pathologist. For this study, there were four groups (detail above in the sample size) of the patient in which controls were tested to recognize the normal value of folic acid, and it was set as the standard. The difference in the folic acid level of groups and control was later observed by the data analysis. The groups were divided as per for evaluating that condition between the new patient, on treating patients and follow-up patients. Controls clarified standard folic acid level and new patients gave an evaluation of lately diagnosed level that did not take concurrent chemoradiation therapy. For stable treatment patients, the folic acid and multi-vitamins dose were suggested that can alter the level.

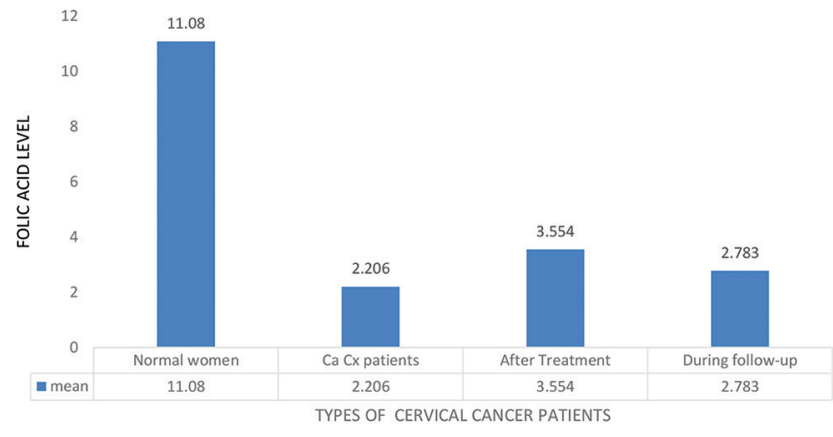

Folic acid estimation

A strong association of $\mathrm{Hb} \%$ which affected to patients in carcinoma cervix can be seen in the graph that the mean value of patients low $11.12 \pm 0.20$ which not comes under the normal range of $\mathrm{Hb} \%$, that is, $12.5 \mathrm{mg} / \mathrm{dl}$. The R square value is 0.9556 .

As per our study, we have estimated that the folic acid level in cervical cancer is low. The -normal range of folic acid level in plasma serum is $2.2-20 \mathrm{ug} / \mathrm{ml}$. The mean of 20 control cases, new cervical cancer patients, on treating patients, and follow-up patients is 11.08, 2.206, 3.554 , and 2.783, respectively. The control 11.08 shows the better level in plasma serum level comes under the normal range of folic acid level. However, the new patients of cervical cancer patients are low and in on-treatment patients are slightly high then new patients and majorly low then control due to folic acid therapy and multivitamin during concurrent and radiation treatment for boosting the immunity and $\mathrm{Hb} \%$ of patients, generally during chemotherapy and concurrent radiation therapy the folic acid level lowered. After completion of treatment the folic acid level below as usual due to poor diet habit, as results of follow-up patients shows. This result shows that consistently low folic acid level in plasma serum in cervical cancer patients in comparison to the normal folic acid level in plasma serum. We observe the folic acid deficiency in cervix cancer patients which is associated with low $\mathrm{Hb} \%$ in blood and that follows anemic condition in these patients. These patients have asked some questionnaire related to dietary habit, we observe that these patients have low or poor diets in their daily routine. By table $\mathrm{Hb} \%$ and basal metabolic rate of cervix cancer patients are also low which is also directly related to folic acid level. 


\section{DISCUSSION}

The major role played by folate is in DNA synthesis and methylation, which leads to DNA reliability in maintenance and also helps in gene expression [15]. The folates have the capability of modulating DNA by the process of methylation, repair, and combination which suggests its role in tumorigenesis. It has been proven in studies that risk factors for cervical intraepithelial neoplasia (CIN) and cervical cancer comprise socioeconomic status, smoking, younger age at first intercourse, race, elevated parity, and use of oral contraceptive [15-18]. In addition to that, growing evidence has concerned nutrients, mainly folate, in the process of cervical carcinogenesis using DNA methylation and fusion $[19,20]$. Some studies [14,21-25], but not all [26], have recommended that folate intake/supplement, as well as levels of folate, plays a crucial role in cervical carcinogenesis.

Folate deficiency has been projected as one of the causative factors in the development of cervical and another type of cancer such as breast, lung, and brain, pancreatic, and colorectal cancers [22]. According to a study, low levels of serum folate might increase the hazard of CIN progression. Besides, potential synergy could exist among low serum folate levels and high-risk HPV infection to encourage CIN expansion [23]. Some other epidemiologic studies have also established the relationship between folate serum and CIN almost all the subjects were small-scale outpatient from different living statuses based on dietary habits and lifestyles [24].

Zhang and contemporaries in their research estimated that elevated homocysteine levels and folate insufficiency, as regulated by serum folate level, can be associated with amplified overall risk of cancer in 83 case-control studies meta-analysis. Hence, it has been clarified that higher or at least sufficient levels have also proven to be protective for cervical cancer. Augmented risk of cervical cancer resulted in deficiency per serum folate in an Asian population, but a similar result was not seen in American cases. Serum levels used to classify deficiency were diverse between several populations, and some were superior to what is reported in the text [25].

Yang et al. in their study estimated that that serum folate is inversely connected with the threat of higher-grade CIN in Chinese women moreover with or without high-risk HPV contamination. Therefore, preservation of normal serum folate levels might establish important for dropping the risk of CIN in patients [26]. The novel approach known as folate receptor-mediated staining solution detection has been planned as effectual testing for CIN and other ovarian cancer. It has been proven higher specificity than HPV and TCT testing $[27,28]$.

The role of folate in cervical carcinogenesis is still uncertain, but facts from epidemiologic data are moderate and are indicating a protective outcome of folate $[29,30]$. A cross-sectional study performed in the United States established that higher circulating folate in the post building up era was connected with a low risk of CIN in the body. Several case-control studies resulted that lack of micronutrients, like folate, had a notably augmented risk of formation of cervical lesions and later, in contrast, other data of case-control and cohort study did not find any connection [31,32].

As per the study of Yang et al., a cross-sectional investigation in 2304 women aged 19-65 years was done. The study indicated that that serum folate is inversely linked with the threat of higher-grade CIN in the Chinese population either with or with no high-risk HPV contagion. This concluded that the maintenance of normal serum folate levels may prove important for reducing the risk of CIN in women [27]. In countries like South-West Nigeria, the study showed that low serum folate is not separately associated with the augmented risk of invasive cervical cancer [33].

\section{Limitation of the study}

In addition, the influential effects of specific nutrients on cervical cancer can be done individually. However, this study also has a limitation.
We only showed the relationships between folate in cervical cancer progression, it indicates that folate may play an essential role in cervical lesions through impacting on DNA methylation and which suppresses the immunity level of the body, low immunity allows HPV and which is main risk factors of cervical cancer which shows by the result in our study.

\section{CONCLUSION}

The fundamental mechanism of folate in the pathogenesis of cervical cancer is not elucidated to date. Folate is involved in the transfer and metabolic development of carbon in the body and is implicated in DNA methylation, playing an important role in the stabilization of the DNA arrangement and the appearance of genes. Low folate levels in the body influence the DNA methylation procedure in cells, which help the DNA chain to fracture and growing chromosome vulnerability. This concludes that if the normal transcription and appearance of DNA are affected; then the risk of cancer cells increases and the growth and prognosis of CIN are inclined.

\section{ACKNOWLEDGMENT}

I pleased to acknowledge "Disha sharma" and "Sudhanshu Mishra" for this research paper and it would be not have been possible without the exceptional support, enthusiasm, inspiration, and knowledge.

I would like to thanks my research Guide Dr. Ranjit Kumar for encouragement throughout this project as well as my clinical guide Dr. Richa Chauhan, Dr. Rita Rani, DrVinita Trivedi head of Radiation Oncology Section Mahavir Cancer Santhan who provide me all research facilities in their laboratory, department, helped me in my research work and for enabling me to get data of cervical cancer and supported me.

\section{AUTHORS CONTRIBUTION}

Km Shanno has completed the lab work and has done the experimentation part. Disha Sharma, Sudhanshu Mishra made the idea and participated in its design and draft of the manuscript. Vikash Chaturvedi helped in the final editing of the manuscript of the research article. All authors read and approved the final draft of the research article.

\section{CONFLICT OF INTEREST}

The authors declared that they have no conflict of interest.

\section{FUNDING}

This research received no specific grant from any funding agency in the public, commercial, or not-for-profit sectors.

\section{REFERENCES}

1. Salina Z, McNamara M, Batur P. Cervical cancer screening: What's new? Updates for the busy clinician. Am J Med 2018;131:702.e1-5.

2. Arulogun OS, Maxwell OO. Perception and utilization of cervical cancer screening services among female nurses in University College Hospital, Ibadan, Nigeria. Pan Afr Med J 2012;11:69.

3. Cohen PA, Jhingran A, Oaknin A, Denny L. Cervical cancer. Lancet 2019;393:169-82.

4. Marquina G, Manzano A, Casado A. Targeted agents in cervical cancer: Beyond bevacizumab. Curr Oncol Rep 2018;20:40.

5. Suleiman M, Yanggau B. Risk Factors for Cervical Cancer: Diagnosis and Management; .

6. Kashyap N, Krishnan N, Kaur S, Ghai S. Risk factors of cervical cancer: A case-control study. Asia Pac J Oncol Nurs 2019;6:308-14.

7. Fotra RO, Gupta SH, Gupta S. Sociodemographic risk factors for cervical cancer in Jammu region of $\mathrm{J}$ and $\mathrm{K}$ state of India first ever report from Jammu. Indian J Sci Res 2014;9:105-10.

8. Petignat $\mathrm{P}$, Roy M. Diagnosis and management of cervical cancer. BMJ 2007;335:765-8.

9. Arbyn M, Weiderpass E, Bruni L, de Sanjosé S, Saraiya M, Ferlay J, et al. Estimates of incidence and mortality of cervical cancer in 2018: A 
worldwide analysis. Lancet Glob Health 2020;8:e191-203.

10. Bray F, Ferlay J, Soerjomataram I, Siegel RL, Torre LA, Jemal A. Global cancer statistics 2018: GLOBOCAN estimates of incidence and mortality worldwide for 36 cancers in 185 countries. CA Cancer J Clin 2018;68:394-424.

11. Fowler JR, Jack BW. Cancer Cervical. Treasure Island, FL: Stat Pearls Publishing; 2020.

12. Gangopadhyay A, Das J, Nath P, Biswas J. Haemoglobin levels may predict toxicities in patients on pelvic chemoradiation for carcinoma of the cervix-experience of a regional cancer centre. Ecancermedicalscience 2014;8:431.

13. Murphy JF. Haemoglobin concentrations for the diagnosis of anaemia and assessment of severity. In: Vitamin and Mineral Nutrition Information System, (WHO/NMH/NHD/MNM/11.1.). Geneva: World Health Organization; 2011.

14. Tiwari KK, Gupta VK. A sensitive spectrophotometric method for the determination of ascorbic acid in biological and pharmaceutical samples. J Indian Counc Chem;25:112-6.

15. Crider KS, Yang TP, Berry RJ, Bailey LB. Folate and DNA methylation: A review of molecular mechanisms and the evidence for folate's role. Adv Nutr 2012;3:21-38.

16. Gillet E, Meys JF, Verstraelen H, Verhelst R, de Sutter P, Temmerman $\mathrm{M}$, et al. Association between bacterial vaginosis and cervical intraepithelial neoplasia: Systematic review and meta-analysis. PLoS One 2012; 7:e45201.

17. Vesco KK, Whitlock EP, Eder M, Burda BU, Senger CA, Lutz K. Risk factors and other epidemiologic considerations for cervical cancer screening: A narrative review for the US preventive services task force. Ann Intern Med 2011;55:698-705, W216.

18. Schiffman M, Castle PE, Jeronimo J, Rodriguez AC, Wacholder S. Human papillomavirus and cervical cancer. Lancet 2007;370:890-907.

19. Appleby P, Beral V, de González AB, Colin D, Franceschi S. International Collaboration of Epidemiological Studies of Cervical C. Carcinoma of the Cervix and Tobacco Smoking: Collaborative Reanalysis of Individual; 2006.

20. Lüthy J. Folate and the risk of colorectal, breast and cervix cancer: The epidemiological evidence. Swiss Med Wkly 2001;131:539-49.

21. Wang Z, Wang J, Fan J, Zhao W, Yang X, Wu L, et al. Risk factors for cervical intraepithelial neoplasia and cervical cancer in Chinese women: Large study in Jiexiu, Shanxi Province, China. J Cancer 2017;8:924-32.

22. Tellouche-Bouhouhou S, Chellat-Rezgoune D, Abadi N, Satta D, Dahdouh A. Methylenetetrahydrofolate reductase c677t gene polymorphism and prostate cancer risk. Asian J Pharm Clin Res
2018;11:387-9.

23. Pieroth R, Paver S, Day S, Lammersfeld C. Folate and its impact on cancer risk. Curr Nutr Rep 2018;7:70-84.

24. Zhao W, Hao M, Wang Y, Feng N, Wang Z, Wang W, et al. Association between folate status and cervical intraepithelial neoplasia. Eur J Clin Nutr 2016;70:837-42.

25. Pathak S, Bhatla N, Singh N. Cervical cancer pathogenesis is associated with one-carbon metabolism. Mol Cell Biochem 2012;369:1-7.

26. Zhou X, Meng Y. Association between serum folate level and cervical cancer: A meta-analysis. Arch Gynecol Obstet 2016;293:871-7.

27. Yang J, Yang A, Wang Z, Wang W, Wang Z, Wang Y, et al. Interactions between serum folate and human papillomavirus with cervical intraepithelial neoplasia risk in a Chinese population-based study Am J Clin Nutr 2017;108:1034-42.

28. Lu MH, Hu LY, Du XX, Yang M, Zhang WY, Huang K, et al. An special epithelial staining agents: Folic acid receptor-mediated diagnosis (FRD) effectively and conveniently screen patients with cervical cancer. Int J Clin Exp Med 2015;8:7830-6.

29. Hu D, Sheng Z, Fang S, Wang Y, Gao D, Zhang P, et al. Folate receptor-targeting gold nanoclusters as fluorescence enzyme mimetic nanoprobesfor tumor molecular colocalization diagnosis. Theranostics 2014;4:142-53.

30. Piyathilake CJ, Macaluso M, Alvarez RD, Bell WC, Heimburger DC, Partridge EE. Lower risk of cervical intraepithelial neoplasia in women with high plasma folate and sufficient Vitamin B12 in the post-folic acid fortification era. Cancer Prev Res (Phila) 2009;2:658-64.

31. Tong SY, Kim MK, Lee JK, Lee JM, Choi SW, Friso S, et al. Common polymorphisms in methylenetetrahydrofolate reductase gene are associated with risks of cervical intraepithelial neoplasia and cervical cancer in women with low serum folate and Vitamin B12. Cancer Causes Control 2011;22:63-72.

32. Yeo AS, Schiff MA, Montoya G, Masuk M, van Asselt-King L, Becker TM. Serum micronutrients and cervical dysplasia in Southwestern American Indian women. Nutr Cancer 2000;38:141-50.

33. Wideroff L, Potischman N, Glass AG, Greer CE, Manos MM, Scott D, et al. A nested case-control study of dietary factors and the risk of incident cytological abnormalities of the cervix Nutr Cancer 1998;30:130-6.

34. Sekumade AI, Okunade KS, Olorunfemi G, Daramola EO, Adenekan MA, Okunowo AA, et al. Association between serum folate level and invasive cervical cancer at a university teaching hospital in South-West Nigeria. J Cancer Res Pract 2019;6:179-83. 